served to prevent the sutures from cutting the raw surface. I think they were quite superfluous in this case, but they are sometimes useful as a form of relaxation suture. It will be noted that it is not a mere skin flap which has been transplanted, but the whole thickness of the sole minus the long tendons. This forms a splendid pad, which should effectually protect the shin against the accidental knocks to which it is liable. The appearance of the stump, with the large and thick flap, was for some time very clumsy and unsightly, but it has greatly improved in the last fortnight, and is already quite neat and sightly. The temperature three times rose above $100^{\circ}$ in the first week, and then sank to normal and remained there. The patient was shown at the Clinical Society on Nov. 13th.

\section{TUBERCLE AND THE TUBERCLE BACILLUS :}

$$
\text { A REVIEW. }
$$

BY H. HANDFORD, M.D., M.R.C.P.,

PHYSICTAN 'TO THE TOTTINGHAM GENERAL HOSPITAL.

Mond than twenty-five years ago Buhl, and a little later Villemin, expressed the view that tubercle was due to the action of a poison generated in the process of caseation of infiammatory products and capable of giving rise to tuberculosis. Cohnheim classed tubercle with the infectious diseases. Klebs, ${ }^{1}$ Schüller, ${ }^{2}$ Toussaint, ${ }^{3}$ and many others searched for a microscopic fungus as the materes morbi and various micrococci and bacteria were discovered which it was thought might prove to be the cause of the disease. It was left, however, for Koch, ${ }^{*}$ in 1882 , to discover the tubercle bacillus by the method of double staining with aniline dyes, to separate it from the other organisms present by the plan of cultivation on solid media, and to reproduce the disease by means of the inoculation of a "pure cultivation" of the bacilli into some of the lower animals. Before proceeding to consider what effect this important discovery has had upon our clinical work, it will be well worth while to spend some time in examining somewhat in detail the results of Koch's more recent Iabours. ${ }^{5}$

The tubercle bacillus requires for its growth a temperature between $86^{\circ}$ and $106^{\circ} \mathrm{F}$. It cannot therefore multiply under natural conditions outside an animal body, at any rate in temperate climates. It reaches its fullest development in about a month, being much more slow of growth than other bacilli. It multiplies by fission, and also by the formation of spores, of which each bacillus may contain from one to three. The spores are set free when the bacillus dies and disintegrates, and are very much more resistant to changes of temperature and to chemical agencies than the bacilli themselves.

The tubercle bacilli are invariably found in actively growing tubercle, in which they are much more numerous than in that which is slowly growing. In the latter they are often confined to the giant cells; in quiescent tubercle they cannot be found.

As regards the different organs, Koch found the bacilli in cases of tubercular ulceration of the tongue, in tubercular disease of the pelvis of the kidney, in the ureter, bladder, uterus, Fallopian tubes, testis, and in tubercular masses in the brain. In scrofulous glands tubercle bacilli were found in most cases, but not in all, and then only in small numbers and confined to the giant cells. In tubercular (scrofulous) disease of the joints and bones tubercle bacilli were found in all the cases examined, but only in small numbers, and confined to the giant cells. Seven cases of indoubted lupus were examined. In all cases inoculation into the anterior chamber of the eye of rabbits produced tubercles on the iris, and eventually general tuberculosis. Four only of the seven specimens were suitable for microscopic examination, and in all of these tubercle bacilli were found, though in very small numbers, and confined to the interior of the giant cells. In one specimen no bacilli were found till after the examination of forty-three sections. In the miliary tuberculosis of man Koch found the bacilli in all of the nineteen cases he examined; the younger and

1 Prag. Med.Wochschr., 1877.22 D. Skroph. u. tuberk. Gelenkleiden. Path. Mittleil.. 1881.

4 D. Ctiologie d. Tuberculose. Berlin. Klin. Wochschr., No. 15, 1882. smaller the nodules, the more numerous the bacilii. In the older caseous nodules few bacilli were found, and these chiefly round the periphery; and in some they seemed to have completely disappeared, perhaps having broken up and left behind their spores. In pulmonary phthisis, also, a relation between the number of bacilli and the activity of the progress of the disease is evident. The bacilli are most numerous in fresh cheesy infiltrations, and in the interior of cavities whose walls are rapidly breaking down. They are less numerous in cavities with dense, indurated walls. In shrunken, cicatricial, deeply pigmented portions of lung tissue they are found most sparingly. Also, the smaller their number the more strictly are they limited to the interior of giant cells. In the walls and in the contents of cavities are found other forms of micro-organisms besides tubercle bacilli, and to some of these, especially to a particular form of micrococcus, pathological signiticance has been attributed. It is supposed that they favour and hasten disintegration and breaking down of the walls of cavities, and it has been shown by Gafiky ${ }^{6}$ that they are fatal to some of the lower animals.

Koch considers the relation of the bacilli to the phthisica process to be approximately as follows. In the first instancel only individual bacilli, or perhaps two or three, enter the lung, and on account of their slow growth are very soon shut in by a cell infiltration, and are thereby prevented from penetrating into the surrounding tissue. The bacilli in the meantime do not perish, but bring about a necrosis and caseation of the centre of the cell mass, just as in miliary tuberculosis. The earliest commencement of phthisis would be exactly like a miliary tubercle, if one could ever succeed in getting a view of it. Gradually the nodule increases in size and becomes more and more unlike a miliary tubercle. Analogous to this stage are the examples of large solitary tubercular masses which are not unfrequently met with, either singly or in small numbers, scattered through the different organs. These must have developed from miliary tubercles too small in number to cause speedy death, as in acute general tuberculosis, but which, having had a longer time to grow, produced caseous masses of considerable size. In the lungs, however, the larger caseous masses take a peculiar course. Sooner or later a communication is formed with a bronchus, thr softened central part escapes, and a cavity is formed. Should the tubercle bacilli by any means escape from the original nodule, they may make their way to other places and there give rise to secondary nodules. This happens in various ways. Sometimes the bacill penetrate the larger pulmonary bloodvessels, are carried by the blood stream all over the body, and set up general miliary tuberculosis. In other cases the bacilli apparently enter the lymphatics, are carried to the bronchial glands, and give rise to secondary tubercular changes in them. It is probable that occasionally a few bacilli may pass through the glands and find their way by means of the thoracic or right lymphatic duct into the blood. By far most frequently the bacilli from cavities are expectorated in the sputum. During this process they may be carried along the bronchi to other parts of the same, or to the opposite lung. Not unfrequently they effect a lodgment in the bronchial walls or in the larynx; often, too, when the sputum is swallowed, in the intestinal canal. And, conversely, primary tubercular disease of the tongue or larynx may give rise to secondary disease of the lungs.

We will next glance as briefly as possible at the differences, in the susceptibility of the various lower animals to the tubercle virus, in the course the disease runs in them, and in the morbid appearances.

As yet no warm-blooded animal has been found to be insusceptible to the tubercular virus, but in almost every species the course and appearances of the disease vary considerably. This is in accordance with the experience of other bacterial diseases. Cattle and some sheep are very sensitive to anthrax; other sheep (Algerian) very much less so. In men, though often fatal, it not unfrequently produces only a local pustule or carbuncle. And dogs are almost, if not quite, insusceptible. The small bacilli of mouse septicæmia, which on inoculation are inevitably and very speedily fatal to mice, produce in rabbits only a local erysipelatous inflammation of the skin. The most striking instance, however, is the difference described by Koch between the house mouse and the field mouse, the one being killed by a bacilıus which is harmless to the other. A some- 
what similar fact is observed in the difference in the course and fatality of measles and other epidemic diseases among civilised and uncivilised races : witness the extreme fatality of measles when it was introduced from Australia into Fiji for the first time, and carried off nearly a third of the population.

Tubercle in cattle ("perlsucht") leads almost always to the production of nodules which do not generally caseate and disintegrate, but calcify, and which by becoming confluent may form large tumours. The most frequent seats of the tubercle nodules are the pleura, pericardium, diaphragm, and peritoneum. In the younger nodules the bacilli may be very numerous; in the older ones they are very few in number and entirely confined to the giant cells.

In the horse tubercle occupies a position midway between the "perlsucht" of cattle and human tuberculosis. The tubercular nodules in the peritoneum and omentum show the greatest similarity to "perlsucht," whereas sections of the lungs in the same cases present completely the appearance of human lungs affected with miliary tuberculosis.

In pigs tubercle is very common, and frequently affects the cervical lymphatic glands, which become caseous. Calcification also occurs. In the lungs a peculiar form of "caseous pneumonia" is met with in which the alveoli are, in places, filled with numerous masses of tubercle bacilli. The origin of these cases is evidently the inhalation of large masses of bacilli.

In sheep and goats Koch only met with one case each. The only point to notice was the existence of a large cavity in each lung, filled with caseous pus, and exactly analogous to the cavities in human lungs.

In fowls tubercle sometimes becomes endemic, and may destroy nearly all the fowls in a brood. Nodules, of firm consistence and very frequently calcified, are found especially in the intestine and liver, but also in the marrow of the bones. Infection seems to take place from the intestine, as nodules are but seldom found in the lungs.

In monkeys tubercle differs in many respects from the same disease in man. As a rule it remains only for a short time limited to one organ, but soon spreads over the whole body. It does not, however, as in human miliary tuberculosis, lead to the formation of numberless small nodules of uniform size, but of a larger or smaller number of tubercular masses of very various size. These are especially frequent in the liver, spleen, and lymphatic glands, and, instead of being composed of a cheesy substance as in the human subject, contain thin pus, and thus resemble multiple abscesses. The presence of the tubercle bacillus shows their true nature. The infection appears to start most frequently in the lungs.

Dogs are very insusceptible, and require large doses of the tubercle virus to render a successful inoculation certain.

Guinea-pigs and rabbits are very sensitive to tubercle, which causes a remarkable enlargement of the spleen and liver, with a peculiar grey or yellow marbled mottling of these organs. They frequently become spontaneously tubercular, and cannot be kept longer than eight or ten months in the same building with tubercular animals without becoming themselves tubercular.

( $T o$ be concluded.)

\section{ON THE FUNCTTON OF THE CILTARY BODY.} BY GEORGE EDWARD WALKER, F.R.C.S.,

SURGEON TO ST. PAUL'S EYE AND EAR HOSPITAL, TO THE SCHOOL FOR THE IYDIGENT BLIND, AND TO THE EOSPITAL FOR SKIN DISEASES, IIVERPOOL.

ALTHOUGH so much has been done, especially of late years, for the elucidation of the duties of the varlous parts of the eye, the function of that complex organ, the ciliary body, is even now by no means well understood. We know that it is composed of three parts-the ligamentum pectinatum, the circular muscle, and the radial muscle. We know that the ligamentum pectinatum is a spongy body capable of admitting a variable quantity of fluid as its meshes are expanded or contracted; that the circular muscle accommodates for nearness, and at the same time opens up the spaces of the ligamentum pectinatum. These points are, I think, not disputed; but of the function of the greater part of the ciliary muscle, the radial fibres, very little has been said or is known. Far accommodation, it is generally maintained, is produced by the mere relaxation of the circular fibres. A few, of whom I am one, maintain that the circular ciliary muscle, like all other circular muscles, is antagonised by a radial muscle; and just as the sphincter ani is opposed by the levator ani, and the orbicularis oris is opposed by the buccinator and other muscles radiating from the mouth, so is the ciliary sphincter antagonised by the ciliary radial muscle, which therefore actively accommodates for distance. For the further illustration of this argument, and, as I submit, also for its proof, I must refer to my essay on Glaucoma. ${ }^{1}$ But if, as appears to be acknowledged, the circular muscle have a double function, may not the radial also have a double function? For the purpose of argument I shall take it for granted that the radial fibres do accommodate for distance, and I shall proceed to show the reasons for my belief that it has a second and even more important duty. Before doing so, however, I think it necessary for the proper understanding of my argument to describe the minute anatomy of the parts concerned. Klein's description is so clear and concise that I make no excuse for copying it verbatim from his admirable "Elements of Histology" (pp. 295, 296):

"The Ligamentum pectinatum iridis is a conical mass of spongy tissue joining firmly the cornea and sclerotic to the iris and ciliary processes. It forms an intimate connexion. on the one hand, with the junction of the cornea and sclerotic, and, on the other, with that of the iris and ciliary processes. This ligament is composed of trabeculit and lamellæ of stiff elastic fibres, forming a continuity, on the one hand, with the lamina Descemeti of the cornea anc the elastic fibres of the sclerotic, and, on the other, with the tissue of the ciliary border of the iris. These trabeculice anastomose so as to form a honeycombed plexus, and the space: in this plexus are lined with a layer of flattened endothelia: cells, directly continued from the endothelium of Descemet's membrane on the one hand, and with the layer of endothelial cells covering the anterior surface of the iris on the other hand." (That is, the ligamentum pectinatum is an elastic, sponge-like body, the cavities of which communicate by open mouths with the anterior chamber.) "At the point of junction of the cornea and sclerotic, but belonging to the latter, and in the immediate neighbourhood of the ligamentum pectinatum iridis, is a circular canal-the cana? of Schlemm; this is lined by endothelium, and is considered by some (Schwalbe) as a lymphatic canal, and by others (Leber) as a venous vessel." (For reasons to be given later, I think the latter is the proper description.) "The ciliary muscle or tensor chorcideæ is fixed to this ligamentum pectinatum; it is composed of bundles of nonstriped muscular tissue. This muscle consists of two parts: $(a)$ one of circular bundles nearest to the iris-this is the portio Mülleri ; $(b)$ the greater part is composed of radiating bundles passing from the ligamentum pectinatum in a meridional direction for a considerable distance backwards into the tissue of the choroid membrane. It occupies the space between the ligamentum pectinatum, sclerotic, ciliary processes, and the adjoining portion of the choroid membrane. The bundles of the muscle are arranged more or less in lamellæ; within each lamella they form plexuses. A rich plexus of non-medullated nerve-fibres, with groups of ganglion cells, belongs to the ciliary muscle."

Waldeyer says that some of the outer fibres are attached to the sclerotic, and of the action of these there can be no doubt, since the scleral attachment must be their fixed point, and the movable point the attachment to the ligament. I believe, and shall endeavour to show later, that the remainder of the meridianal fibres act in the same manner. the choroidal attachment being the fixed or almost fixed point, and the ligamental attachment the movable one. So that the ciliary muscle, so far from being the tensor choroidex merely, is also the tensor of the ligament.

Although it seems to be impossible to estimate accurately

Donders in his classic work speaks in opposition to this theory, and says that the subjective sensation for himself is conclusive. Pace tont viri, this argument cuts both ways. I am both hypermetropic and astigmatic, and therefore have to accommodate a good deal even ior distance. I have acquired such control orer mi ciliary muscles that can see-saw between the two with almost as much ease as betwetn the biceps and triceps of my arm; that is to sar. I can contract my radia? muscle so that the whole of my hypermetropia and astigmatism becomes manifest, just as would take place if the ere were fully under tive influence of atropine, and the next moment. in spite of my hrpe"metropia and incipient presbrotir, I can read "brilhant" type. 